\title{
Craniosynostosis-intracranial calcifications syndrome
}

INSERM

\section{Source}

INSERM. (1999). Orphanet: an online rare disease and orphan drug data base.

Craniosynostosis-intracranial calcifications syndrome. ORPHA:52054

Craniosynostosis-intracranial calcifications syndrome is a form of syndromic craniosynostosis characterized by pancraniosynostosis, head circumference below the mid-parental head circumference, mild facial dysmorphism (prominent supraorbital ridges, mild proptosis and maxillary hypoplasia) and calcification of the basal gang lia. The disease is associated with a favorable neurological outcome, normal intelligence and is inherited in an autosomal recessive manner. 